San Jose State University

SJSU ScholarWorks

Master's Theses

Master's Theses and Graduate Research

1993

\title{
The Effects of proprioceptive training on postural sway using the Biomechanical Ankle Platform System on healthy subjects
}

Mark Hoffman

San Jose State University

Follow this and additional works at: https://scholarworks.sjsu.edu/etd_theses

\section{Recommended Citation}

Hoffman, Mark, "The Effects of proprioceptive training on postural sway using the Biomechanical Ankle Platform System on healthy subjects" (1993). Master's Theses. 630.

DOI: https://doi.org/10.31979/etd.8sqw-z5wm

https://scholarworks.sjsu.edu/etd_theses/630

This Thesis is brought to you for free and open access by the Master's Theses and Graduate Research at SJSU ScholarWorks. It has been accepted for inclusion in Master's Theses by an authorized administrator of SJSU ScholarWorks. For more information, please contact scholarworks@sjsu.edu. 


\section{INFORMATION TO USERS}

This manuscript has been reproduced from the microfilm master. UMI films the text directly from the original or copy submitted. Thus, some thesis and dissertation copies are in typewriter face, while others may be from any type of computer printer.

The quality of this reproduction is dependent upon the quality of the copy submitted. Broken or indistinct print, colored or poor quality illustrations and photographs, print bleedthrough, substandard margins, and improper alignment can adversely affect reproduction.

In the unlikely event that the author did not send UMI a complete manuscript and there are missing pages, these will be noted. Also, if unauthorized copyright material had to be removed, a note will indicate the deletion.

Oversize materials (e.g., maps, drawings, charts) are reproduced by sectioning the original, beginning at the upper left-hand corner and continuing from left to right in equal sections with small overlaps. Each original is also photographed in one exposure and is included in reduced form at the back of the book.

Photographs included in the original manuscript have been reproduced xerographically in this copy. Higher quality 6" x 9" black and white photographic prinis are available for any photographs or illustrations appearing in this copy for an additional charge. Contact UMI directly to order.

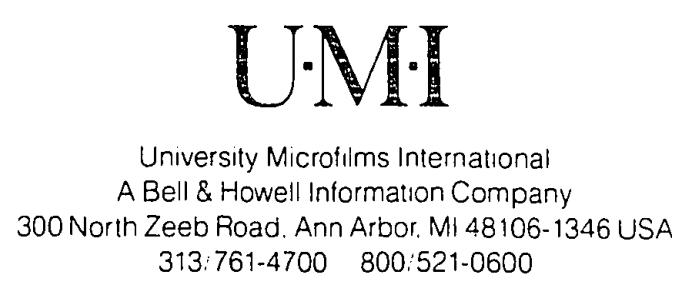


The effects of proprioceptive training on postural sway using the Biomechanical Ankle Platform System ${ }^{\mathrm{TM}}$ on healthy subjects

Hoffman, Mark, M.A.

San Jose State University, 1993 


-


THE EFEECTS OF PROPRIOCEPTIVE TRAINING ON POSTURAL SWAY USING THE BIOMECHANICAL ANKLE PLATFORM SYSTEM ${ }^{\text {Th }}$ ON HEALTHY SUBJECTS

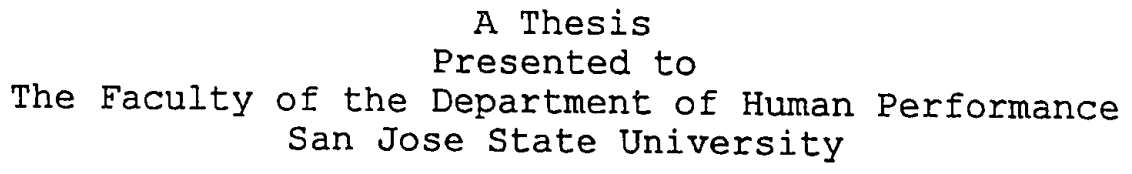

In Partial Fulfillment

of the Requirements for the Degree Master of Arts

By

Mark Hoffman

August, 1993 
APPROVED FOR THE DEPARTMENT OF HUMAN PERFORMANCE
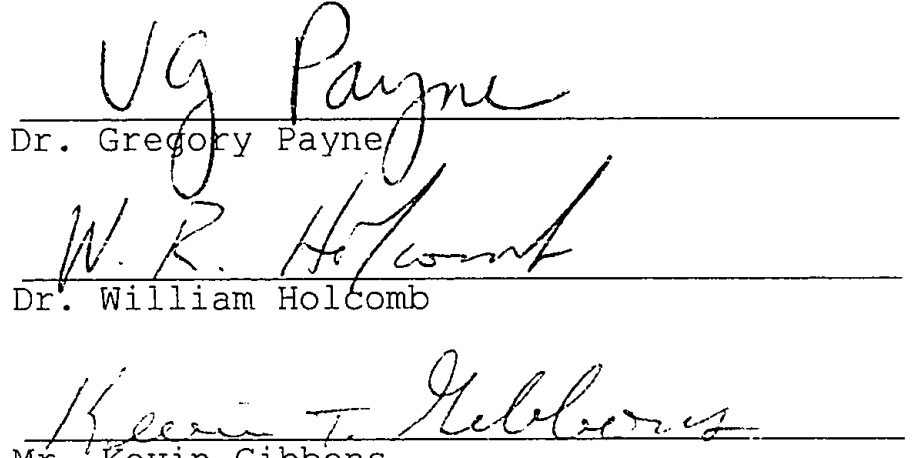

Mr. Krevin Gibbons

APPROVED FOR THE UNIVERSITY

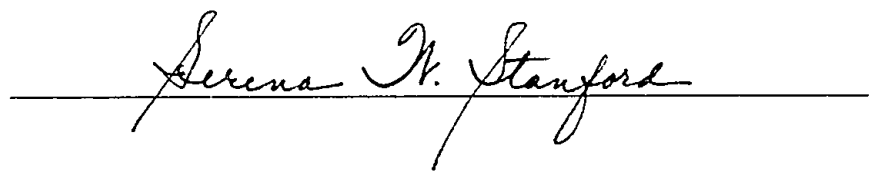




\section{ABSTRACT}

THE EFFECTS OF PROPRIOCEPTIVE TRAINING ON POSTURAL SWAY USING THE BIOMECHANICAL ANKLE PLATFORM SYS [EM ${ }^{\text {TH }}$ ON HEALTHY SUBJECTS

By Mark Hoffman

The use of proprioceptive training is commonly used in the rehabilitation of subjects with lower extremity injuries. The use of proprioceptive training enables injured subjects to reduce proprioceptive deficits, and increase their ability to maintain postural control. The effects of proprioceptive training has not been researched in healthy subjects.

The purpose of this study was to investigate the effects Biomechanical Ankle Platform System ${ }^{\mathrm{TM}}$ training, on the postural sway of healthy subjects $(\mathrm{N}=28)$. Subjects were pre tested on the Kistler force platform while standing on the bare foot of the dominant leg in a modified romberg position. Subjects trained 3 times per week for 10 weeks. Following post testing significant differences were found on both the medial-lateral (X) and anterior-posterior (Y) parameters of postural sway. In conclusion, 10 weeks of proprioceptive ankle disk training significantly decreased postural sway in both the medial-lateral and anteriorposterior directions. 


\section{Acknowled.jments}

I would like to acknowledge and exte ld my appreciation to the following people.

To my parents, whom I love dearly, for their continued love and support during my educational enilevors.

To Dr. Greg Payne for believing in m?, helping me become a quality resercher, and accepting the responsibility of committee chairperson.

To Dr. Bill Holcomb for his support ind for serving on my committee.

To Kevin Gibbons for his true intres: in my educational development and for serving on my conmittee.

To Leonard Giacalone (a.k.a. "The Le I Man") and Cindy Fontaine (a.k.a. "TC") for love, supsort, and putting up with me and my messes during my work.

To Dr. David Koceja, Dr. David Schiel,, and Steve Reisenhouver for their patience and villingness to help during the project. 


\section{TABLE OF CONTENTS}

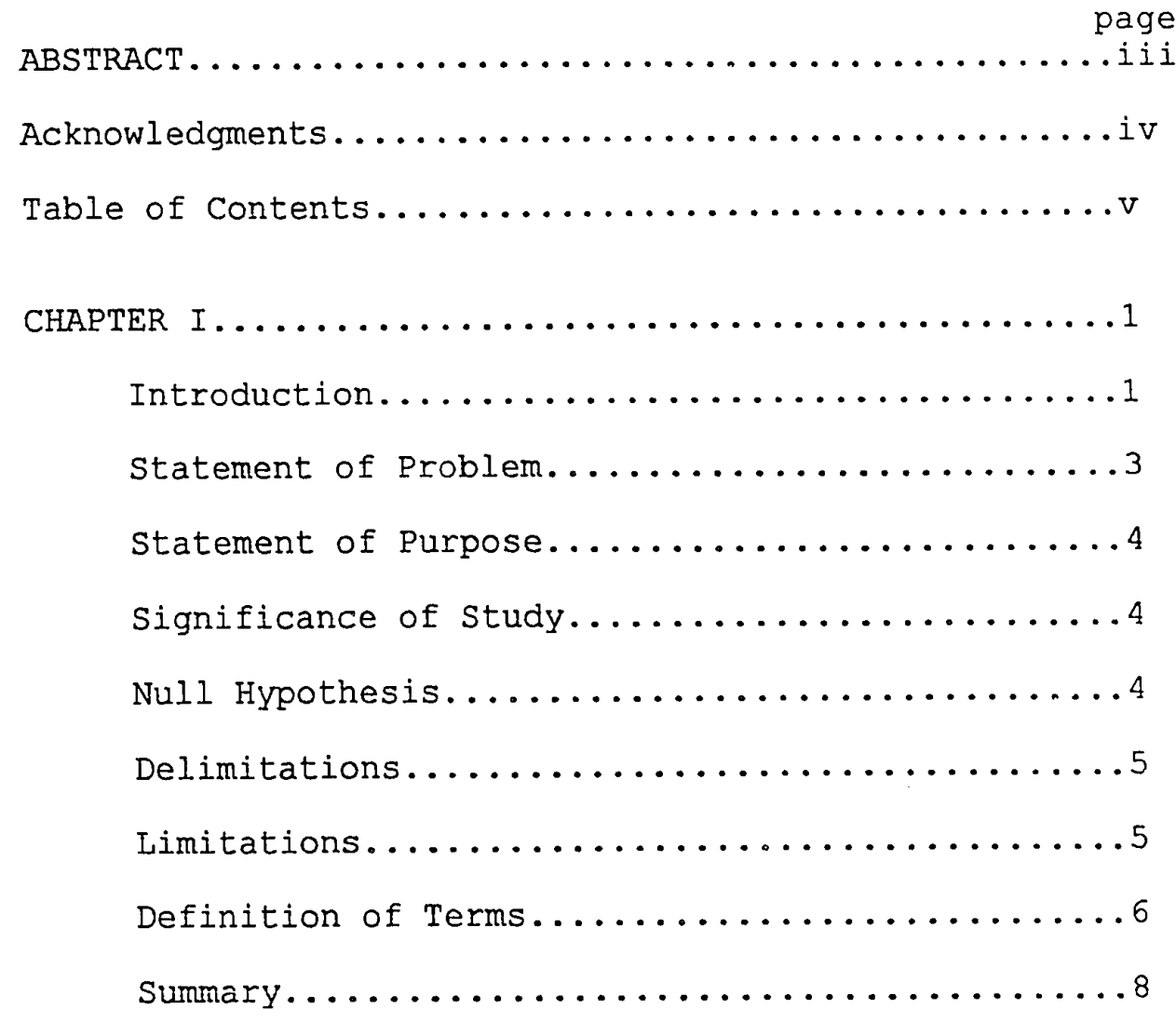

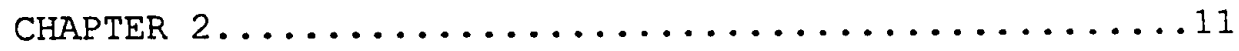

REVIEW OF LITERATURE.....................

Introduction........................

Proprioception....................11

Anatomy/Physiology...................... 16

Proprioceptive Defects................22 
Injury Prevention......................

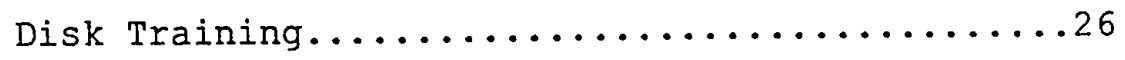

Summary............................

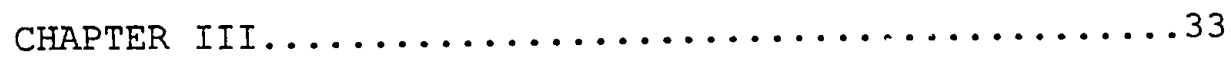

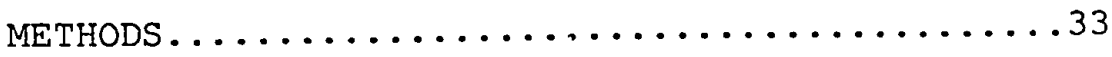

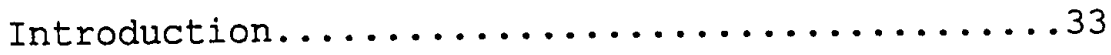

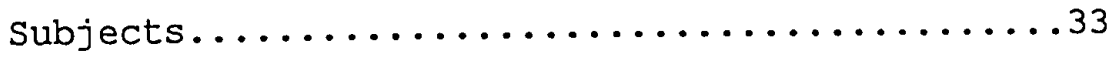

Experimental Protocol......................

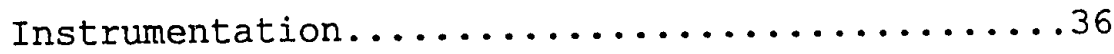

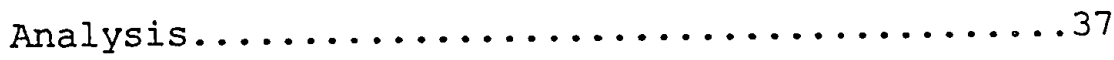

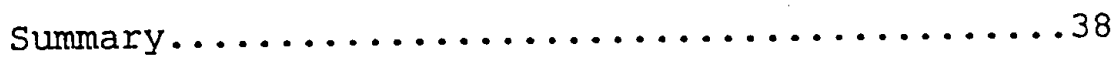

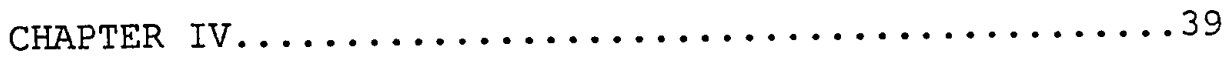

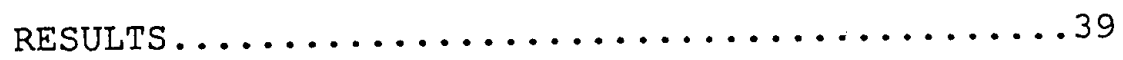

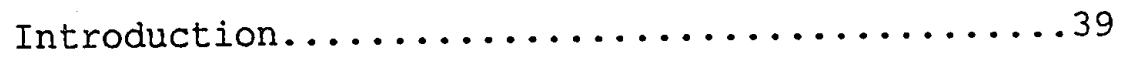

Subjects/Training .......................

Proprioceptive Testing................41

CHAPTER $r \ldots \ldots \ldots \ldots \ldots \ldots \ldots \ldots \ldots \ldots \ldots \ldots \ldots . \ldots \ldots$

SUMMARY, DISCUSSION, CONCLUSIONS, and

RECOMMENDATIONS...................49

Introduction.....................49

Summary........................... 49

Discussion.......................... 50

vi 
Conclusion......................... 51

Recommendations.................... 52

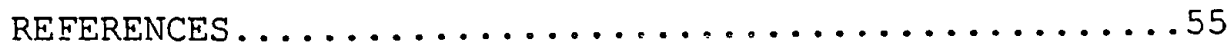

APPENDICES......................... 58

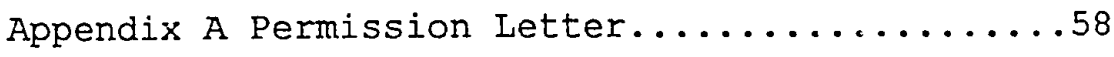

Appendix B Agreement to Participate in

Research................60

Appendix C Potential Subject Information Sheet..63

Appendix D Subject Information Sheet........65

Appendix E Tests Used to Determine Dominance...67

Appendix F Kistler Force Platform and Modified Romberg Test...............68

Appendix G Biomechanical Ankle Platform

system $^{\mathrm{TM}} \ldots \ldots \ldots \ldots \ldots \ldots \ldots \ldots \ldots$ 


\section{LIST OF TABLES}

Table 1 Subject and Training Data..........40

Taile 2 Experimental Group: X Parameter

Data....................43

Table 3 Experimental Group: Y Parameter

Data......................44

Table 4 Control Group: X Parameter Data......45

Table 5 Control Group: Y Parameter Data......46

Table 6 Single-Factor ANOVA for $\mathrm{x}$

Parameter....................47

Table 7 Single-Factor ANOVA for $Y$

Parameter..................48 
CHAPTER I

INTRODUCTION

Ankle injuries are the most commonly reported injuries in running and jumping sports (Balduini \& Tetzlaff, 1982). Chronic functional instabilities often result from ankle sprains and are characterized by the subjective complaint of the ankle "giving way" during normal activities (Freeman \& Wyke, 1967; Gauffin, Tropp, \& Odenrick, 1988; Tropp, Askling, \& Gillquist 1985; Tropp, Ekstrand, \& Gillquist, 1984a). Proper treatment and rehabilitation facilitate the return of an athlete to activity and decrease the incidence of re-injury. The two most common causes for residual ankle instabilities that can be addressed by rehabilitation are peroneal muscle weakness and proprioceptive defects (Lentell, Kratzman, \& Walters, 1990).

The peroneal muscles are located on the lateral side of the lower leg. They evert and plantar-flex the foot and ankle (Hoppenfeld, 1976). Minor weakness is commonly found in the peroneal muscle group of the lower leg following injury (Lentell et al., 1990). This weakness decreases the subject's ability to dynamically stabilize the ankle during activity. 
Historically, ankle injury care and prevention have focused on muscular strengthening, while neglecting the other major cause of ankle instabilities, proprioceptive deficits. In recent years, more emphasis has been placed on proprioceptive training which has been shown to reduce the incidence of functional instabilities and prevent the reoccurrence of ankle injuries (Freeman, Dean, \& Hanham, 1965; Gauffin et al., 1988; Tropp, Askling, \& Gillquist, 1985; Tropp, Ekstrand, \& Gillquist, 1984b). Proprioceptive ankle disk training was designed to assist in re-educating the proprioceptive mechanism to minimize coordination problems (Freeman et al., 1965; Gauffin et al., 1988; Tropp, Askling, \& Gillquist, 1985; Tropp et al., 1984b).

Ereeman et al. (1967) suggested that functional instabilities of the foot and ankle are due to motor incoordination. They concluded that decreased coordination results from articular deafferentation caused by afferent mechanoreceptor damage that occurs during injury. During ankle disk coordination training the damaged afferent joint receptors are re-educated and the muscles are strengthened (Freeman et al., 1967; Glencross \& Thorton, 1981).

Proprioceptive deficits were first quantitatively measured by Freeman et al. (1965), using a modified Romberg test. The modified Romberg test measures postural sway 
which is a direct measure of proprioception and an indicator of proprioceptive defects (De Carlo, Rettig, \& Talbot, 1986; Sahlstrand, Ortebgren \& Nachemson, 1978; Tropp et al., 1984). Sahlstrand et al. (1978) refined a specific detailed protocol for the quantitative investigation of postural sway, using a force platform, that has been widely adopted for research (De Carlo et al., 1986; Gauffin et al. 1988; Tropp et al. 1984a; Tropp, Askling \& Gillquist, 1985; Tropp, Odenrick \& Gillquist, 1985;).

\section{Statement of Problem}

Injuries to joint connective tissues can damage afferent mechanoreceptors causing disruption of the proprioceptive mechanism (Freeman et al., 1967). As stated earlier, ankle disk coordination training increases proprioception in subjects with a history of ankle injuries (Freeman et al., 1965; Gauffin et al., 1988; Tropp, Askling, \& Gillquist, 1985; Tropp et al., 1984b). However, similar research has not been conducted to determine if proprioceptive ankle disk coordination training can benefit subjects without previous injury. If healthy subjects can increase their proprioception, then the incidence of functional instabilities may decrease. 


\section{Statement of Purpose}

The purpose of this study was to investigate the effects of a training program using the Biomechanical Ankle Platform system (BAPS ${ }^{\text {ru }}$ ) on proprioception of subject.s without a history of lower extremity injury.

\section{Significance of Study}

Prevention of athletic injuries may be the most difficult aspect in the realm of athlete care. This is especially true in the case of ankle injuries, which are the most commonly reported athletic injuries (Garrick, 1977). Tropp, Askling and Gillquist (1985) reported that 178 of all soccer injuries were ankle sprains. If the initial injury can be prevented by increcising proprioception through ankle disk coordination training, then the incidence of functional instabilities in the athlete should ultimately be reduced.

\section{Null Hypothesis}

Following a 10 week period of BAPS $^{\text {TM }}$ training, subjects will show no significant change in proprioception as measured by postural sway evaluation on the force platform. 


\section{Delimitations}

The following delimitations existed in this investigation:

1. Subjects had no history of injury to the lower extremity or known balance related conditions.

2. Subjects ranged in age from 14 to 19 .

3. Volunteers were accepted from a high school student population.

4. The proprioceptive training tool was the Biomechanical Ankle Platform system (BAPS ${ }^{\text {Tu }}$ ).

5. The force platform was used to measure postural sway (proprioception).

\section{Limitations}

The following were limitations applied to the current study:

1. Determination of the subject's dominant side was based on three functional tests: preferred kicking leg test, stair test, and balance recovery test. While these tests are commonly employed, they are not infallible.

2. Use of $\mathrm{BAPS}^{\mathrm{T}}$ as a training tool was a limitation to the study because there is no existing research to document 
that the BAPS ${ }^{\mathrm{T}}$ promotes proprioception and decreases postural sway.

3. Determination of proprioceptive changes through force plate evaluation was a limitation because it is based on a research assumption that indicates postural sway is a direct measure of proprioception.

4. Subject motivation could not be controlled.

\section{Definition of Terms}

The following definitions will be used in this study and are presented here for clarification.

Anterior Drawer Sign- An orthopedic ligamentous stress test designed to test the integrity of the anterior talofibular ligament and performed by stabilizing the tibia and fibula while manually drawing the talus and foot forward (Arnheim, 1989; Hoppenfeld, 1976; McGee, 1987; Roy \& Irvin, 1983).

Dominant Side- The side of the body determined dominant in two out of the three following tests: subject selected side used to kick a ball, subject selected side first used in climbing stairs, and subject selected side used to stabilize the body when balance is disturbed (Appendix E).

Force Platform- A device used to quantify postural sway that responds to projection on the horizontal base plane of 
the movements of the body's center of gravity (Sahlstrand et al., 1978) .

Functional Instability- A condition characterized by the subjective complaint of "giving way" commonly seen as a residual symptom of ankle injury. Functional instabilities may be present in the absence of mechanical instabilities (Tropp, Odenrick, \& Gillquist, 1985).

Healthy Subject- Subjects having no known history of vestibular disturbances or lower extremity injury where symptoms persisted longer than 7 days.

Kinesthesia- The ability to discriminate joint position, relative weight of body parts, and joint movements including, direction, amplitude, and speed (Newton, 1982).

Mechanical Instabilities- The presence of a positive anterior drawer test of the ankle joint (Tropp, Odenrick, \& Gillquist, 1985).

Mechanoreceptors- Afferent nerve receptors found in structures surrounding joints of the body. They produce impulses that travel to the spinal cord through dorsal nerve-roots, and project to the cerebellum. They function in the perception of posture and motion. Their feedback is essential in the control of muscular contraction and body movement (Freeman et al., 1967). 
Postural Sway- Postural sway is a naturally occurring phenomenon that occurs in the sagittal and lateral planes. It represents a complex reflex process, involving the acquisition and processing of sensory information and execution of motor commands (Sahlstrand et al., 1987).

Proprioception- The awareness of posture, movement, and changes in equilibrium and the knowledge of position, weight, and resistance to objects in relation to the body (Davis, 1985). It enables the muscles to vary their contraction forces in immediate response to fluctuations in the rotary moments of force that develop at the joint of the foot and the entire lower extremity during locomotion. Properly innervated muscles function together to control the amount of joint motion as they also prevent motion from occurring outside the normal plane of motion of the joint (Gray, 1986).

Stabilometery- An objective, quantitative mathod for studying postural control or sway during a modified Romberg test on a force platform (Sahlstrand et al., 1987)

\section{Summary}

The most commonly reported injuries in running and jumping sports are ankle injuries (Balduini \& Tetzlaff, 1982). In the past, ankle injury treatment and 
rehabilitation have focused primarily on strengthening the ankle musculature. Presently, ankle treatment and rehabilitation target muscle strengthening and proprioceptive training. Proprioceptive training is now emphasized because research has shown that proprioceptive deficits exist following injury to the ankle joint and surrounding structures, and that ankle disk training decreases the deficit (Freeman et al., 1967; Gauffin et al., 1988; Tropp, Askling, \& Gillquist, 1985; Tropp et al., $1984 b)$.

Proprioceptive training which has been demonstrated to prevent the reoccurrence of ankle injuries has not been studied in healthy subjects (Freeman et al., 1967; Gauffin, et al., 1988; Tropp, Askling, \& Gillquist, 1985; Tropp, et al., 1984b). Proprioceptive ankle disk training promotes re-education of the proprioceptive mechanism and can be quantified by evaluation of the Romberg test on the force plate.

The modified Romberg test, tests postural sway, a direct measure of proprioception and an indicator of proprioceptive defects (De Carlo, et al., 1986; Sahlstrand, et al., 1978; Tropp et al., 1984a). If healthy subjects are capable of increasing proprioception in the lower limb, the incidence of functional instabilities may decrease. 
The purpose of this study was to investigate the effects of ankle disk coordination training on proprioception of subjects without history of lower extremity injury, using the Biomechanical Ankle Platform system $\left(\right.$ BAPS $\left.^{\mathrm{TM}}\right)$.

The effects of ankle disk coordination training programs have not yet been thoroughly researched in healthy subjects. If healthy subjects can train proprioceptively, the incidence of injury may be reduced (Soderberg, Cook, Rider, \& Stephenitch, 1991). 
CHAPTER II

REVIEW OF LITERATURE

\section{Introduction}

The purpose of this study was to investigate the effects of ankle disk coordination training on proprioception of subjects without history of lower extremity injury. In this chapter, related literature is presented. Initially, a discussion of the pertinent anatomy and physiology will be reviewed. Next, studies and literature related to proprioceptive defects and functional instabilities of the ankle are discussed. Information related specifically to ankle disk training and BAPS $^{\mathrm{TM}}$ is reviewed in the third section of this chapter. Becalse considerable research on proprioception and its measurement has evolved in recent years the fourth section presented in this chapter is a review of commonly used and accepted measures of proprioception. A summary concludes the chapter.

\section{Proprioception}

The terminology used in the discussion of proprioception often varies. Therefore, standard definitions of proprioception and kinesthesia must be 
presented. Proprioception is the component of postural control that is responsible for keeping the body's center of gravity within the area of support through coordination of afferent and efferent nerve activity and muscle fiber function. Kinesthesia, on the other hand, is "the ability to discriminate joint position; relative weight of body parts, and joint movements including, direction, amplitude, and speed" (Newton, 1982, p. 27). Only the components of kinesthesia directly related to proprioception are addressed in this review.

Historically, proprioception has been difficult to measure. Freeman et al. (1965) reported that functional instabilities of injured ankles, decreases in postural control, and proprioception could be determined from a modified Romberg test. However, in two studies conducted by Tropp (Tropp et al., 1984b; Tropp, Odenrick, and Gillquist, 1985), injured limb proprioceptive values obtained by having the subjects perform a modified Romberg test on a force platform were not significantly different from non-injured limb values. Tropp and counterparts adopted a stabilometric protocol designed by Sahlstrand et al. (1978) which evaluated postural sway in both the frontal and sagittal planes. 
Frontal plane, not sagittal piane, deviations of the center of pressure have been reported to be a more accurate indicator of proprioceptive deficits than an average of the two values (Friden, Zatterstrom, Lindstrand, \& Moritz, 1989). Friden et al. (1989) conducted a study of patients with acute ankle sprains to determine if there was an increase of postural sway in the frontal plane, which was believed to be a direct indicator of a proprioceptive deficit. These researchers referenced previous research that reported a high correlation between the movement of other body segments (such as the sternum, hip, and knee) in the frontal plane, and movement of the center of pressure in the frontal plane. Based on past research, these researchers developed a new protocol. It focused solely on the movements of the center of pressure in the irontal plane as measured using the force platform. With this new protocol, the authors felt that error in postural sway measure was decreasıd because it eliminated sagittal sway values. By eliminating the sagittal sway values from the calculation of tota. sway, frontal sway became the actual indicator of proprinception.

They tested 55 healthy subjects bilaterally to obtain reference group valies. The experimental group was comprised of 14 subiects (10 male and 4 female) with acute 
ankle ligament lesions. The subjects were tested with and without a brace between three and eight days post-injury. The modified Romberg test on a force platform was used to assess proprioception.

Measurements of six parameters were recorded. In the first parameter (mean value of the distance between the center of pressure and the reference line on the force platform) there was no significant difference between injured and uninjured ankles. Parameter II (the standard deviation of Parameter I) measured the amplitude but not the frequency of the movements. There was a significant correlation between increased sway and injury and the authors concluded that Parameter II could discriminate well between injured and uninjured. In Parameter III, where frequency and amplitude of movement were recorded, a correlation greater than .7 indicated that this parameter could be used to discriminate between injured and uninjured ankles. The authors reported that Parameter IV, measured values similar to Parameter II, but with less sensitivity. In Parameter V and VI number of sway amplitudes exceeding 5 and $10 \mathrm{~mm}$, respectively), significance was found in both Parameter $\mathrm{V}$ and $\mathrm{VI}$ allowing the authors to use these parameters to differentiate between injured and uninjured ankles. 
The reliability and validity of force platform evaluations have long been concerns of researchers. In a study by Goldie, Bach, and Evans (1989) these concerns were addressed. They stated the validity of using any of several force platform measure has not been established. Three basic indices have been used historically in force platform research: measures of the variability of horizontal forces, measures of the variability of the center of pressure, and measurements of the total excursion of the center of pressure. Another concern is that no external criterion exists in which validity can be established. Reliability of measures have been based solely on empirical findings, and no research exits that has compared the reliability of different measures.

The purpose of Goldie's study (1989) was to investigate the correlations between different measures of postural control on the force platform, to examine the retest reliability of measures, and to establish sensitivity of the different measures. Twenty-eight volunteers (mean age 28.1) who were free of balance related problems and leg injury within three months of being tested were tested, in 14 different stances with eyes opened and closed. The trials were $32 \mathrm{~s}$ in length and the sampling frequency was $40 \mathrm{~Hz}$. 
In regard to the testing stance to be used in this study (preferred leg with eyes open) the results showed the variability of medial-lateral, and anterior-posterior forces were the two most sensitive (valid) measures of stability. These two measures also resulted in the highest values of retest reliability. The normative values (force variability) for the rnedial-lateral and anterior-posterior were calculated to be approximately $2.8 \pm .6$ and $2.0 \pm .6 \mathrm{~N}$ (approximate values taken from chart). In conclusion, the authors reported that movements in the frontal plane were indicative of injury. They felt previous similar studies failed to yeild significant differences because of the stabilometric technique used.

\section{Anatomy/Physiology}

Newton (1982) discussed the anatomy, physiology, and specific characteristics of the four types of afferent receptors acting on joints of the body. He also discussed the role of mechanoreceptors in detecting joint angle, reflex responses, and kinesthesia. According to Newton (1982), Type I, Type II, and Type III receptors are recognized as "true" joint receptors because they detect joint stress and have a direct action targeted at relieving that stress. Type IV receptors are classified as pain 
receptors and are not "true" joint receptors because they function solely to detect stress and initiate a pain signal. AlI four types of receptors are found in or around diarthrodial joints and their supporting non-contractile tissues. The concentration and distribution of these mechanoreceptors varies between joints and species (Newton, 1982).

Type I receptors, typically found on the joint capsule and collateral ligaments, have static and dynamic function. They provide constant sensory feedback to the central nervous system independent of the activity at the joint level. They are slow adapting sensory endings with a low threshold of activation (Newton, 1982).

Type II receptors are found primarily in two locations: the junction of the synovial membrane at the joint capsule, and in the joint's fat pads. They occur at highest concentrations in distal joints on the medial and lateral. aspects. Type II receptors are dynamic with a low threshold of activation that rapidly adapt to changes in the joint. They are activated via a stretch or deformation of the joint capsule (Newton, 1982).

The largest of the receptors are the Type III. Found only in joints of the extremities, they are highly concentrated in the collateral ligaments. They are 
characterized by a high threshold of activation and slow adaptation to change. These dynamic Type III receptors are typically active only at extreme degrees of active or passive joint ranges or during high levels of longitudinal stress (Newton, 1982).

Type IV receptors function as pain receptors and may be found in ligaments, capsules, or fat pads. They are characterized by free or lattice type endings that are slow adapting and have a high threshold of activation. Normally they are active only during extreme mechanical deformation, direct chemical (algesic substances), or mechanical irritation (Newton, 1982).

The connection between joint receptors and muscular activity supports the involvement of joint receptors in reflexive responses. As mentioned above, reflexive responses are a coordination of joint receptors and muscular activity (Newton, 1982).

The function of the Type I receptor is to detect speed and direction of movement of the joint. Because Type II receptors are rapidly adapting, they are capable of detecting small and accelerating movements. Type III receptors are reported to function as detectors of joint position and direction of motion. A unique interaction between the receptors provides proprioceptive feedback 
needed for coordination and reflex activities (Newton, 1982).

In 1967 Freeman and Wyke published a landmark study that targeted the influence of mechanoreceptors upon reflex and muscular activity. They evaluated the motor unit activity of a cat's hind leg during passive movements using electromyographic studies. Specifically, they evaluated the reflex input from the cat ankle joint capsule's mechanoreceptor to the related motor neurons.

Passive ankle plantar flexion and dorsiflexion of anesthetized cats were performed through an angle of $150^{\circ}$ during electromyographic analysis. Resection of skin, removal of tendons, and other invasive procedures were conducted to remove sensory input from other receptors, and to isolate the sensory activity of the joint mechanoreceptors. An increase in the level of general anesthesia depressed other involved reflexes (Freeman et al., 1967):

The conclusions of this study set the foundation for much of the research that has been conducted on mechanoreceptors. Freeman et al. (1967) concluded: 1) corpuscular end-organs in the ankle joint act as slow and rapidly adapting mechanoreceptors, 2) introducing local anesthesia into the ankle joint of the cat causes 
interruption of mechanoreceptor afferent functions and abolishes articular reflexes during passive joint movements, 3) articular mechanoreceptor reflexes may operate polysynaptically by way of the gamma motor neuron loop (Freeman et al., 1967).

In an attempt to test Freeman's theory, Glencross et al. (1981) conducted a study to determine if proprioceptive defects exist following ankle injury. The goal of their study was to report the effects of joint injury on the ability to reposition the ankle to a previously established position.

The researchers studied 24 subjects, 13 males and 11 females, between the ages of 18 and 24 . All subjects were at least eight months post injury, had full range of motion, were pain free, and denied recent injury. Subjects were divided into three groups according to their severity of injury rated by the o'Donaghue scale. The testing procedure evaluated the subjects ability to reposition the ankle to a previously established joint angle. Multiple joint angles were tested, and the injured ankle was compared to the uninjured ankle of each subject.

The results showed a significant decrease in the ability to reposition the injured ankle to the previously 
demonstrated joint position. There were no significant findings related to the severity of injury.

In conclusion, the authors reported that ankle injuries decrease joint position sense. The authors also stressed the need for rehabilitation, which they concluded is as much a relearning process as a physical recovery phase (Glencross \& Thorton, 1981).

In another study to test Freeman's deafferentation theory, De Carlo et al. (1986) conducted a study on the effects of local anesthesia on proprioception at the ankle. A local injection of Xylocaine was introduced into the anterior talofibular ligament of the ankle of 24 healthy subjects (12 male and 12 female) in an attempt to induce deafferentation. According to Freeman's theory of deafferentation, postural sway as measured by a modified Romberg test should increase as deafferentation occurs. The effect of repeated testing of the subjects was the only area of testing that showed statistical significance. There were no significant differences between the injected and the non-injected ankles of the subjects.

In conclusion, the authors reported the lack of significance was due to poor testing apparatus construction. They reported that since the apparatus did not allow full range of motion of the ankle joint, not all of the joint 
receptors, especially Type I and Type II, could be accurately tested. However, the authors demonstrated that through repeated testing on the apparatus proprioception can be learned.

\section{Proprioceptive Defects}

A study conducted by Tropp, Odenrick and Gillquist (1985) evaluated the correlation between mechanical and functional instabilities of the ankle joint. They included 25 male soccer teams from a swedish soccer division. Eighteen players from each team were selected, six players were excluded due to recent severe injury. Of the remaining 444 players, 47 were randomly selected for stabilometry evaluations. The protocol described by Sahlstrand et al. (1978) for stabilometry evaluation was adopted for the study. Functional instabilities were defined subjectively as the ankle giving way. Mechanical instabilities were defined as a positive anterior drawer of the arkle. Thirteen percent of the mechanically stable ankles exhibited functional instabilities. Of the 47 subjects selected for stabilometry, 29 ankles had functional instabilities; 18 of these 29 showed significantly higher stabilometery recordings. Of the 18 ankles without functional instabilities, only 4 showed an increase of 
postural sway in the post test. There were no differences in stabilometry readings based on the presence or absence of mechanical instabilities (Tropp, Odenrick, \& Gillquist, 1985).

In another study eviluating kinesthesia and balance of injured subjects, Garn and Newton (1988) tested Freeman's deafferentation theory. They used 30 subjects who self reported at least two spiains of one ankle and no injury to the other ankle. The purpose was to test Freeman's theory, which stated that kinesthesia and balance would decrease due to mechanoreceptor damagr. following ankle injury (Freeman et al., 1965). Garn and Newton (1988) hypothesized that there would be no decrease in either kinesthesia or balance between the injured and uninjured sides of each subject.

All subjects in the study (24 males and 6 females) reported at least two lateral ankle sprains in one ankle while the other ankle had no history of injury. A kinesthesiometer was used to passively move the subjects ankle at a speed of $.3^{\circ}$ per $s$, and balance was subjectively measured using a one-legged standing balance test.

The procedure consisted of 30 trials on each ankle (15 trials of no movement and 15 trials of movement). The subjects were to respond "yes" or "no" at the end of each trial when asked if movement had occurred. Balance was 
tested using two $30 \mathrm{~s}$ trials on each leg (one with eyes open and one with eyes closed). Following the completion of the trials, the subject reported which leg resulted in the most difficulty in balancing.

The results from this investigation showed a decrease in the accuracy of detecting passive movement in ankles with multiple sprains. In 53\% of the subjects balance was perceived to be: worse on the injured leg. The results caused the authors to reject their hypothesis and accept Freeman's theory (Garn \& Newton, 1988).

\section{Injury Prevention}

Ankle orthosis and coordination training on an ankle disk have been reported to decrease the incidcnce of injury of players with a history of ankle injury. Orthoses protect the ankle mechanically while coordination training protects functionally (Tropp, Askling, \& Gillquist, 1935).

Tropp, Askling, and Gillquist (1985) conclucted a study that involved 25 male swedish soccer teams. Eighteen subjects were chosen from each team $(N=450)$. They were divided into three groups. Group one was the control, group two was the orthosis group, and group three was the coordination training group. In group three, only those 
players with previous injury participated in the training $(N=65)$.

The coordination training, for the first 10 weeks, was 10 min sessions, 5 times per week. Following the initial 10 weeks, the athletes continued to train for $5 \mathrm{~min}, 3$ times per week for the duration of the season.

The results showed that both injured ankle disk training and wearing an orthosis reduced injury rates. Sprains were more frequent in the athletes with previous injury than in athletes with no history of injury (Tropp, Askling, \& Gillquist, 1985).

In yet another study using stabilometery, prediction of injury based on stabilometric values was evaluated. Prediction plays a major role in the prevention of injury, and Tropp et al. (1984b) reported that stabilometery may be used as a predictor of injury. They also report this to be the only known study relating stabilometery and injury rates.

The control group consisted of 30 active males with no history of injury to the lower leg. This group was used to establish normative stabilometery values for comparison to the test group in this study.

The test group was composed of a senior soccer division with 180 players (12 teams), but 53 were excluded for 
various reasons. All subjects were examined for old injuries which were classified as an injury that required either hospital care, medical consultation, or absence from practice or competition for more than one week. Stabilometric values were obtained on all subjects prior to the start of regular season activity.

The results showed that 29 of the 127 (23\%) players had pathological stabilometery readings and that 23 of the 127 subjects sustained an ankle injury (18\%). Of the 29 subjects with proprioceptive defects, 12 sustained an ankle injury for a $42 \%$ incidence of injury. Conversely, 98 of the 127 (77\%) subjects had normal stabilometric recordings when compared to the control group. Of these 98 subjects, only 11 sustained an injury to the ankle (11\% injury incidence). In conclusion, the authors reported that soccer players with functional instabilities, as measured by stabilometery, have an increased risk of injury.

\section{Disk Training}

In one of the first studies conducted to determine the effects of coordination disk training, Freeman et al., (1965) compared the treatment effects of immobilization, conventional physical therapy, and physical therapy with an emphasis on coordination training. The period $0:=$ 
immobilization was three weeks long with partial weight bearing. The conventional physical therapy group received treatment that targeted pain control and muscle strengthening. The group that underwent coordination training was required to proprioceptively train on balance boards similar to the BAPS ${ }^{\text {TH }}$.

In conclusion, the authors reported that there were significant decreases in the subjective and objective instabilities in proprioceptive training group as measured by the modified Romberg test. The other modes of treatment did not prove to be significant in reducing instabilities. Gauffin et al. (1988) showed that functional instabilities and proprioceptive defects can be decreased through proprioceptive ankle disk coordination training. The major conclusion made by the authors was that functional instabilities result from a disturbance in the central control mechanism for posture. This theory disputes Freeman's theory of functional instabilities. The basis for Freeman's theory is that functional instabilities result from damage to the afferent mechanoreceptors of the joint involved.

The study examined 10 males with subjective complaints of functional instabilities. All subjects underwent eight weeks of ankle disk training. None had ever been trained 
proprioceptively. The training period was $10 \mathrm{~min}$ at a rate of 5 times per week for 8 weeks. Proprioceptive defects (postural sway), were measured using a combination of the force plate and video analysis. The force plate measured the variance of the center of pressure from the origin of the $X$ and $Y$ axis, while the video analysis, analyzed compensatory movements of the trunk and limbs to maintain postural equilibrium.

The results showed decreases in the distance of movement of the center of pressure and a decrease in the amplitude of the movements on the force plate. The video analysis confirmed the increase in postural control. following ankle disk coordination training. The authors also reported decreased stabilometric values when the subjects were tested on the unaffected leg.

In conclusion, decreases in stabilometric values have been reported by many authors. The results of the video analysis indicated that proprioceptive training may increase the efficiency of the central postural control mechanism, not the function of the afferent mechanoreceptors, as previously reported by Freeman et al. (1967).

Mechanoreceptor damage causing ankle injuries and functional instabilities were also studied by Tropp et al. (1984a). In their study, they sought to determine if 
functional instabilities were caused by acute ankle sprains, and to determine if the functional instabilities could be decreased by ankle disk coordination training or ankle taping.

Three groups of subjects were studied. One group had acute ankle sprains. A second group had functional instabilities and trained on an ankle disk. A third group of subjects with functional instabilities were taped prophylacticlly for the study. The acute ankle sprain group was proprioceptively tested once. The subjects were tested as soon following injury as pain and swelling would allow. The training group was tested twice. The first test was prior to a training period of six weeks at a frequency of 15 min every day. The subjects trained both the affected and the unaffected legs. The ankle taping group subjects were tested with and without tape to eliminate situational variations.

The results showed no significant difference between the injured and the uninjured leg. The ankle disk coordination training group decreased postural sway in both the affected and the unaffected limbs. There were no significant differences in the subjects of the taping group. In conclusion, there was no evidence that acute injury caused functional instabilities. Also, no significance was 
found in the effect of ankle taping on postural sway. However, ankle disk coordination training significantly decreased postural sway in the affected and the unaffected Iimbs causing the author to support the theory that postural control is a central control pattern.

The issue of determining the mechanism of an increased postural sway following ankle injury has been the primary focus of past ankle proprioceptive research. However, a study conducted in 1991 focused on the effects of ankle disk training of healthy and injured subject's lower leg musculature (Soderberg et al., 1991). Twenty-eight subjects (14 injured and 14 healthy) participated in the study designed to measure subject's myoelectrical activity of the lower leg muscules while the subject rotated on the BAPS ${ }^{\text {tu }}$. The results of an analysis of variance showed no significant differences between the injured and non-injured groups. The authors reported that normal and injured lower legs respond the same during use of the BAPS ${ }^{\text {rx }}$. They also reported that varying the difficulty of the task, by changing the size of the hemisphere used under the board, changed muscular activity patterns in the same way in both injured and non-injured ankles. In addition, changing the direction of rotation changed muscular activity patterns. 


\section{Summary}

Proprioception is defined as the component of postural control that is responsible for keeping the body's center of gravity within the area of support through coordination of afferent and efferent nerve activity and muscle fiber function. There are four types of joint mechanoreceptors involved in the proprioceptive feedback loop (Newton, 1982). Freeman et al. (1967) stressed the importance of mechanoreceptors in reflexes and muscular activity. Freeman et al. (1967) formed the "Freeman's deafferentation theory" which stated that a proprioceptive deficit exists following injury to joint mechanoreceptors.

A decrease in proprioception or postural control can be quantified using a force platform (Tropp et al., 1984a), and having the subject perform a modified Romberg test (Freeman et al., 1965). The most significant information obtained from a modified Romberg test is postural sway in the frontal plane (Friden et al., 1989).

In an attempt to test Freeman's theory, Garn and Newton (1988) studied subjects with a history of ankle sprains of one ankle and no injury to the ipsilateral ankle. The results from their investigation caused them to accept Freeman's theory. 
Ankle disk training has been shown to reduce proprioceptive deficits (Tropp, Askling, \& Gillquist, 1985). They compared the effects of ankle disk training and ankle orthosis and concluded that ankle disk training was more effective in injury prevention than ankle braces. Freeman et al. (1965) compared the effects of immobilization, conventional physical therapy, and physical therapy with an emphasis on coordination training. They found that significant decreases in the subjective and objective instabilities as measured by the modified Romberg test in subjects who proprioceptively trained.

In conclusion, proprioceptive deficits exist following injury to the afferent nerve receptors of joints. These deficits can be reduced by the implication of proprioceptive disk training and injury rate may be reduced through the same mode of training. 
CHAPTER III

METHODS

\section{Introduction}

The purpose of this study was to investigate the effects of ankle disk coordination training, using the Biomechanical Ankle Platform System $\left(\right.$ BAPS $^{\text {tu }}$ ), on proprioception of subjects without a history of lower extremity injury.

In this chapter, the methods are presented. Initially, subject selection, and requirements are discussed. Followed by an explanation of experimental protocol and the related instrumentation. Next, a brief discussion of statistical considerations and applications are presented.

\section{Subjects}

The subjects in this study were male and female students at Homestead High School in Cupertino, CA. Thirtysix subjects volunteered to participate. This population was selected because it represented a population that may benefit from proprioceptive training. The purpose and the experimental protocol were explained to all subjects. Prior to possible enrollment as subjects, the volunteers were allowed and encouraged to ask questions about the study. Written permission from Homestead High School was obtained 
before the initiation of the subject search (Appendix A). Prior to participation in the study, the subjects and the parents or guardians, of those under 18 years of age, were required to give informed consent meeting the requirements of the San Jose State University Institutional Review Board of Human Subjects (Appendix B). When subjects were assigned to their experimental group, they were given a number. The only person with knowledge of the subject's name and number was the primary researcher.

Potential subjects were screened through the use of a participant information form (Appendix C) prior to participation in the study. If the subjects reported a history of lower leg injury with symptoms which lasted more than one week, they were excluded from the study. Subjects were also excluded if they indicated the presence of a balance related disorder.

\section{Experimental Protocol}

The subjects were required to read and sign a human subject informed consent form (and obtain parental permission when under the age of 18 years of age) (Appendix B) in accordance with University policy.

on the first testing date, subject age, sex, and weight were obtained (Appendix D), and leg dominance was determined 
through the implementation of three functional tests (Appendix E). Prior to the pre-test, subjects were randomly assigned to either the experimental or control group. The pre-test stabilometery recordings were obtained using the modified Romberg test on the Kistler force platform. The modified Romberg test used in this study positioned the subject standing on their dominant bare foot with the opposite hip held in a self selected position. A visual focus light source was placed $3 \mathrm{~m}$ in front of the subject. Prior to the beginning of measurement, the subjects were allowed to test this position for $20 \mathrm{~s}$. Trials were $26 \mathrm{~s}$ in length. Following the pre-test, the subjects were introduced to the BAPS $^{\text {TM }}$ training, and testing schedules were established.

The training sessions were approximately $10 \mathrm{~min}$ in length. Training started on the lowest progression of the BAPS $^{\text {Ts }}$, and progressed according to subject a oility determined by a progression test. Although upper body stabilization was allowed during the training, emphasis was placed on minimizing such assistance. The subjects were instructed to place the foot of the leg being trained on the BAPS $^{\text {Tu }}$ and rotate at a self selected speed. The initial direction of rotation was subject selected, and changed every $10 \mathrm{~s}$ of the $40 \mathrm{~s}$ trial. Five trials were completed 
every session. Before a subject was allowed to move to a more difficult level of BAPS $^{\mathrm{TM}}$ progression, they were required to successfully complete a progression test. The test consisted of having the subject perform a $20 \mathrm{~s}$ trial with no upper body stabilization. During their progression test, direction was switched once on the command of the tester. If the subject was able to perform the test without a loss of balance, they were allowed to progress to the next training level.

The training period was 10 weeks long and three times per week (30 sessions). Absence from more than three training sessions eliminated the subjects from the study. Following ten weeks of training, the subjects were retested on the force platform.

\section{Instrumentation}

Two pieces of equipment were used in this study. The first was the Kistler Force platform (Appendix F) and the second was the Biomechanical Ankle Platform system (BAPS ${ }^{\text {tu}}$ ) (Appendix G) .

The force platform was used to measure postural sway. The foot was placed at the origin of an established reference line. As the subject stood on the force platform in the modified Romberg position for $26 \mathrm{~s}$, measurements of 
medial-lateral and anterior-posterior were recorded at a frequency of $50 \mathrm{~Hz}$. The middle $20 \mathrm{~s}$ of data (1000 samples) were used in the calculation of results.

The Biomechanical Ankle Platform System ${ }^{\text {Tu }}$ was used as the proprioceptive training device in this study. The shape and design of the platform was based on anatomical, neurological, and biomechaincal considerations, and was designed to allow proportional amounts of motion in all ankle planes of motion (Gray, 1986).

Analysis

Each subject trial consisted of 1000 data points for the $\mathrm{X}$ and $\mathrm{Y}$ parameters. Standard deviations for both parameters were calculated to give a sway varability value for both the $X$ and $Y$ parameters in each trial. The three values, one from each trial, for each parameter were then averaged to produce the mean sway varability (MSV) for the $\mathrm{X}$ and Y parameters for each subject (Goldi et al., 1989). Following the calcuation of the MSVs, the pre and post values for each subject were compared and gain scores calculated. An ANOVA was applied to the gain scores to test the hypothesis that no change would be experienced by the experimental group compared to the control. 
Summary

The purpose of this study was to investigate the effects of ankle disk coordination training on proprioception of subjects without history of lower leg injury.

Subjects were high school students who were required to meet the study's definition of "healthy" subject and complete the required consent forms.

Subjects were pre and post tested on the Kistler force platform to determine postural control. Following the pretest, the subjects in the experimental group trained for 10 weeks using the BAPS $^{\text {Tu }}$ while subjects in the control did not train. At the end of the training period, the post-tests were conducted, and the data statistically analyzed. Statistical analysis included standard deviations of both the medial-lateral $(\mathrm{X})$ and the anterior-posterior ( $\mathrm{Y}$ ) parameters were conducted to obtain the mean sway value (MSV;. An ANOVA was applied to the gain scores for each dependant variable to determine overall significance of results between the experimental and control groups. 
CHAPTER IV

RESULTS

Introduction

The effects of proprioceptive ankle disk training on postural sway of healthy subjects using the BAPS ${ }^{\text {T* }}$ were investigated in this study. Postural sway, an indicator of proprioception, was quantified through the use of the force platform. Measures of mean sway variability (MSV) were calculated for each subject in the medial-lateral (X), and the anterior-posterior directions (Y). The amount of change from pre to post testing for both parameters was calculated for each subject. An Analysis of Variance (ANOVA) was applied to the gain scores of each parameter at an alpha level of .05 to determine if there was a significant treatment effect. Additional descriptive statistics were calculated.

Subjects/Training

Thirty-four male and female high school students from Homestead High School agreed to participate in the study. Four of the subjects did not meet the healthy subject participation criteria and two subjects did not complete the study for personal reasons resulting in a subject number of 28 (females $=12$, males $=16$ ). Table 1 presents descriptive 
Table 1

Subject and Training Information

\begin{tabular}{|c|c|c|c|c|c|}
\hline $\begin{array}{l}\text { Subject } \\
\text { Number } \\
1 E\end{array}$ & $\begin{array}{c}\text { Gender } \\
\text { F }\end{array}$ & $\begin{array}{c}\text { Age } \\
\text { (yr) } \\
17\end{array}$ & $\begin{array}{c}\text { WT } \\
(\mathrm{kg}) \\
57\end{array}$ & $\begin{array}{c}\text { Dominant } \\
\text { Leg } \\
\text { L }\end{array}$ & $\begin{array}{c}\text { Final BAPS } \\
\text { Level } \\
3\end{array}$ \\
\hline $2 \mathrm{E}$ & $\mathrm{M}$ & 17 & 115 & $\mathrm{R}$ & 5 \\
\hline $3 E$ & $\mathrm{M}$ & 16 & 94 & $\mathrm{R}$ & 4 \\
\hline $5 E$ & $\mathrm{M}$ & 17 & 80 & $\mathrm{R}$ & 4 \\
\hline $6 \mathrm{E}$ & $\mathrm{M}$ & 17 & 103 & L & 3 \\
\hline $7 E$ & $\mathrm{M}$ & 16 & 70 & L & 4 \\
\hline $8 E$ & M & 18 & 102 & $\mathrm{R}$ & 4 \\
\hline $9 E$ & $F$ & 16 & 54 & $\mathrm{R}$ & 3 \\
\hline $10 \mathrm{E}$ & $\mathrm{M}$ & 17 & 70 & $\mathrm{R}$ & 3 \\
\hline $11 \mathrm{E}$ & $\mathrm{M}$ & 18 & 87 & $\mathrm{R}$ & 4 \\
\hline $12 E$ & $\mathrm{M}$ & 18 & 76 & $\mathrm{R}$ & 3 \\
\hline $13 E$ & M & 15 & 68 & $L$ & 4 \\
\hline $14 \mathrm{E}$ & $\mathrm{F}$ & 17 & 59 & $\mathrm{R}$ & 4 \\
\hline $15 E$ & $\mathrm{~F}$ & 15 & 55 & I & 3 \\
\hline $1 \mathrm{C}$ & $\mathrm{M}$ & 15 & 81 & $\mathrm{R}$ & - \\
\hline $2 C$ & $\mathrm{~F}$ & 18 & 55 & R & - \\
\hline $3 C$ & $\mathrm{M}$ & 17 & 84 & $I$ & - \\
\hline $4 \mathrm{C}$ & $\mathrm{F}$ & 15 & 63 & $\mathrm{R}$ & - \\
\hline $5 C$ & $\mathrm{~F}$ & 18 & 60 & $\mathrm{R}$ & - \\
\hline
\end{tabular}




\begin{tabular}{|c|c|c|c|c|c|}
\hline & & & & \multicolumn{2}{|c|}{ (table continues) } \\
\hline $\begin{array}{l}\text { Subj } \\
\text { Number }\end{array}$ & Gender & $\begin{array}{l}\text { Age } \\
\text { (yr) }\end{array}$ & $\begin{array}{l}\text { WT } \\
(\mathrm{kg})\end{array}$ & $\begin{array}{c}\text { Dominant } \\
\text { Leg }\end{array}$ & $\begin{array}{c}\text { Final BAPS } \\
\text { Level }\end{array}$ \\
\hline $7 \mathrm{C}$ & $\mathrm{F}$ & 17 & 62 & $\mathrm{I}$ & - \\
\hline $8 C$ & $F$ & 15 & 61 & $\mathrm{R}$ & - \\
\hline $9 \mathrm{C}$ & $\mathrm{M}$ & 15 & 101 & $\mathrm{R}$ & - \\
\hline $10 \mathrm{C}$ & M & 16 & 67 & $\mathrm{R}$ & - \\
\hline $11 \mathrm{C}$ & M & 17 & 67 & $\mathrm{R}$ & - \\
\hline $12 \mathrm{C}$ & F & 15 & 56 & $\mathrm{R}$ & - \\
\hline $13 \mathrm{C}$ & M & 17 & 75 & $\mathrm{R}$ & - \\
\hline $14 \mathrm{C}$ & F & 15 & 47 & $\mathrm{R}$ & - \\
\hline $15 \mathrm{C}$ & $\mathrm{F}$ & $\underline{14}$ & $\underline{55}$ & $\mathrm{R}$ & - \\
\hline & & 16.4 & 72.3 & & \\
\hline & & 1.1 & 17.8 & & \\
\hline
\end{tabular}

and demographic information of the subjects $(\mathrm{N}=28)$. The mean age of the subjects was $16.4 \pm 1.1$ years. All of the subjects reached at least level 3 (of 5 levels) while only one subject reached level 5. Seventy-five percent of the subjects were right leg dominant.

Proprioceptive Testing

Sway variability was measured during three trials and the MSV was calculated for each subject pre-training (Tables 3 and 4 ) and post training (Table 5 and 6). The average $x$ 
and $Y$ force values for pre testing were $3.05 \pm 1.15$ and 2.51 \pm .86 , respectively, compared to the post values of $2.56 \pm$ .83 for $X$ and $2.19 \pm .72$ for $Y$. The effect size for the $X$ parameter was .22 and .47 for the $Y$ parameter. The average changes between pre and post testing in the experimental and control groups for the $X$ parameter were $.82 \pm .96$ and $.15 \pm$ .55, respectively. For the $Y$ parameter the values were $.50389 \pm .544028$ for the experimental compared to $.124808 \pm$ .154178 for the control.

The ANOVA for the $\mathrm{X}$ parameter (Table 6) resulted in a significant difference, $F(1,26)=5.09, p=.033$. Significance was also found in the $Y$ parameter, $F(1,26)=6.29, \underline{p}=.019$ (Table 7). 
Table 2

Experimental Group Pre Training X Parameter Descriptive Data

\begin{tabular}{|c|c|c|c|c|}
\hline Subject & Gender & Pre $\mathrm{X}$ & Post $\mathrm{X}$ & Change in \\
\hline Number & & IASV (N) & MSV (N) & MiSV (N) \\
\hline $1 E$ & $\mathrm{~F}$ & 2.95 & 1.75 & 1.20 \\
\hline $2 \mathrm{E}$ & M & 4.73 & 3.31 & 1.42 \\
\hline $3 \mathrm{E}$ & $\mathrm{M}$ & 4.17 & 3.45 & 0.72 \\
\hline $5 E$ & M & 5.68 & 2.80 & 2.88 \\
\hline $6 \mathrm{E}$ & M & 3.40 & 2.75 & 0.65 \\
\hline $7 \mathrm{E}$ & M & 4.05 & 1.77 & 2.28 \\
\hline $8 \mathrm{E}$ & M & 3.89 & 4.66 & -0.77 \\
\hline $9 \mathrm{E}$ & $\mathrm{F}$ & 2.57 & 2.02 & 0.55 \\
\hline $10 \mathrm{E}$ & M & 2.38 & 2.14 & 0.24 \\
\hline $11 \mathrm{E}$ & M & 5.15 & 3.68 & 1.47 \\
\hline $12 \mathrm{E}$ & M & 2.92 & 2.75 & 0.17 \\
\hline $13 \mathrm{E}$ & M & 2.59 & 2.49 & 0.10 \\
\hline $14 \mathrm{E}$ & $\mathrm{F}$ & 2.05 & 1.49 & 0.56 \\
\hline $15 E$ & $\mathrm{~F}$ & 2.09 & 2.07 & 0.01 \\
\hline & & 3.47 & 2.65 & 0.82 \\
\hline & & 1.16 & 0.88 & 0.96 \\
\hline
\end{tabular}

$\mathrm{N}=\mathrm{Newtons}$ 
Table 3

\section{Experimental Group Pre Training $Y$ Parameter}

Descriptive Data

\begin{tabular}{|c|c|c|c|c|}
\hline $\begin{array}{c}\text { Subject } \\
\text { Number } \\
1 E\end{array}$ & Gender & $\begin{array}{c}\text { Pre Y } \\
\text { MSV (N) } \\
2.06\end{array}$ & $\begin{array}{c}\text { Post Y } \\
\text { MSV (N) } \\
1.49\end{array}$ & $\begin{array}{c}\text { Change in } \\
\text { MSV (N) } \\
0.57\end{array}$ \\
\hline $2 E$ & $M$ & 4.16 & 3.16 & 1.00 \\
\hline $3 \mathrm{E}$ & M & 2.90 & 3.16 & -0.26 \\
\hline $5 \mathrm{E}$ & $M$ & 4.41 & 2.82 & 1.58 \\
\hline $6 \mathrm{E}$ & M & 3.64 & 2.60 & 1.04 \\
\hline $7 \mathrm{E}$ & $\mathrm{M}$ & 2.57 & 1.51 & 1.06 \\
\hline $8 E$ & M & 3.70 & 3.68 & 0.02 \\
\hline $9 \mathrm{E}$ & $\mathrm{F}$ & 2.06 & 1.77 & 0.29 \\
\hline $10 \mathrm{E}$ & $\mathrm{M}$ & 2.04 & 1.93 & 0.11 \\
\hline $11 \mathrm{E}$ & M & 3.81 & 2.98 & 0.82 \\
\hline $12 \mathrm{E}$ & M & 2.66 & 2.43 & 0.22 \\
\hline $13 E$ & $\mathrm{M}$ & 2.20 & 2.36 & -0.16 \\
\hline $14 \mathrm{E}$ & F & 1.73 & 1.06 & 0.67 \\
\hline $15 E$ & $F$ & 2.07 & 1.98 & $\underline{0.09}$ \\
\hline & & 2.86 & 2.35 & 0.50 \\
\hline & & 0.91 & 0.76 & 0.54 \\
\hline
\end{tabular}

$\mathrm{N}=$ Newtons 
Table 4

Control Group Post Training X Parameter

Descriptive Data

$\begin{array}{ccccc}\begin{array}{c}\text { Subject } \\ \text { Number }\end{array} & \text { Gender } & \begin{array}{c}\text { Pre X } \\ \text { IC C (N) }\end{array} & \begin{array}{c}\text { Post X } \\ \text { MSV (N) } \\ 4.27\end{array} & \begin{array}{c}\text { Change in } \\ \text { MSV (N) }\end{array} \\ \text { 2C } & \text { F } & 2.34 & -0.07 \\ \text { 3C } & \text { M } & 3.06 & 2.27 & 0.80 \\ \text { 4C } & \text { F } & 2.61 & 2.45 & 0.16 \\ \text { 5C } & \text { F } & 2.54 & 2.85 & -0.31 \\ \text { 7C } & \text { F } & 1.51 & 1.38 & 0.13 \\ \text { 8C } & \text { F } & 1.74 & 2.22 & -0.49 \\ \text { 9C } & \text { M } & 4.78 & 3.34 & 1.44 \\ 10 \mathrm{C} & \mathrm{M} & 2.74 & 2.60 & 0.14 \\ 11 \mathrm{C} & \mathrm{M} & 2.51 & 3.18 & -0.67 \\ 12 \mathrm{C} & \mathrm{F} & 1.70 & 1.74 & -0.05 \\ 13 \mathrm{C} & \mathrm{M} & 3.00 & 2.31 & 0.69 \\ 14 \mathrm{C} & \mathrm{F} & 1.12 & 1.36 & -0.24 \\ 15 \mathrm{C} & \mathrm{F} & \underline{3.11} & \underline{2.79} & \underline{0.32} \\ & & 2.63 & 2.48 & 0.15 \\ & & 1.01 & 0.81 & 0.55\end{array}$

$\mathrm{N}=\mathrm{Newtons}$ 
Table 5

\section{Control Group $Y$ Post Training Parameter}

Descriptive Data

\begin{tabular}{|c|c|c|c|c|}
\hline $\begin{array}{c}\text { Subject } \\
\text { Number } \\
\text { 1C }\end{array}$ & $\begin{array}{c}\text { Gender } \\
\text { M }\end{array}$ & $\begin{array}{c}\text { Pre Y } \\
\text { MSV (N) } \\
3.80\end{array}$ & $\begin{array}{c}\text { Post Y } \\
\text { MSV (N) } \\
3.64\end{array}$ & $\begin{array}{c}\text { Change in } \\
\text { MSV (N) } \\
0.16\end{array}$ \\
\hline $2 \mathrm{C}$ & $\mathrm{F}$ & 1.47 & 1.37 & 0.10 \\
\hline $3 C$ & $M$ & 2.59 & 2.56 & 0.03 \\
\hline $4 C$ & $F$ & 2.19 & 2.15 & 0.04 \\
\hline $5 \mathrm{C}$ & $\mathrm{F}$ & 1.89 & 1.67 & 0.22 \\
\hline $7 \mathrm{C}$ & $F$ & 1.56 & 1.24 & 0.32 \\
\hline $8 \mathrm{C}$ & $\mathrm{F}$ & 1.54 & 1.66 & -0.11 \\
\hline $9 \mathrm{C}$ & M & 2.95 & 2.72 & 0.23 \\
\hline $10 \mathrm{C}$ & M & 2.40 & 2.26 & 0.14 \\
\hline $11 \mathrm{C}$ & M & 2.33 & 2.45 & -0.12 \\
\hline $12 \mathrm{C}$ & $\mathrm{F}$ & 2.04 & 1.71 & 0.33 \\
\hline $13 \mathrm{C}$ & M & 2.19 & 1.84 & 0.35 \\
\hline $14 \mathrm{C}$ & $F$ & 1.12 & 1.10 & 0.02 \\
\hline $15 \mathrm{C}$ & $\mathrm{F}$ & 2.22 & 2.17 & $\underline{0.05}$ \\
\hline & & 2.16 & 2.04 & 0.12 \\
\hline & & 0.68 & 0.68 & 0.15 \\
\hline
\end{tabular}

$\mathrm{N}=$ Newtons 
Table 6

Single-Factor ANOVA for X Parameter (MSVs)

Experimental

Change (X)

1.20

0.55

1.42

0.24

$0.72 \quad 1.47$

$2.88 \quad 0.17$

$0.65 \quad 0.10$

$2.28 \quad 0.56$

$-0.77$

0.01
Control

Change ( $X$ )

$-0.07 \quad 1.44$

$0.28 \quad 0.14$

$0.80 \quad-0.67$

$0.16-0.05$

$\begin{array}{ll}-0.31 & 0.69\end{array}$

$0.13-0.24$

$\begin{array}{ll}-0.49 & 0.32\end{array}$

Summary

Groups Count Sum of Average Variance

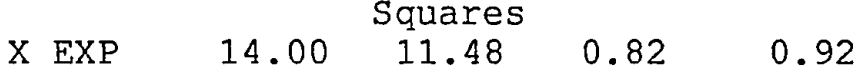

$\begin{array}{lllll}X \text { CONT } & 14.00 & 2.14 & 0.15 & 0.30\end{array}$

Sources of Variation

$\begin{array}{llllll}\text { SS } & \text { df } & \text { MS } & \text { F crit }\end{array}$

$\begin{array}{lllllll}\text { Between } & 3.11 & 1.00 & 3.11 & 5.09 & .03 & 4.23\end{array}$

Within $\quad 15.89 \quad 26.00 \quad 0.61$

Total $\quad 19.00 \quad 27.00$ 


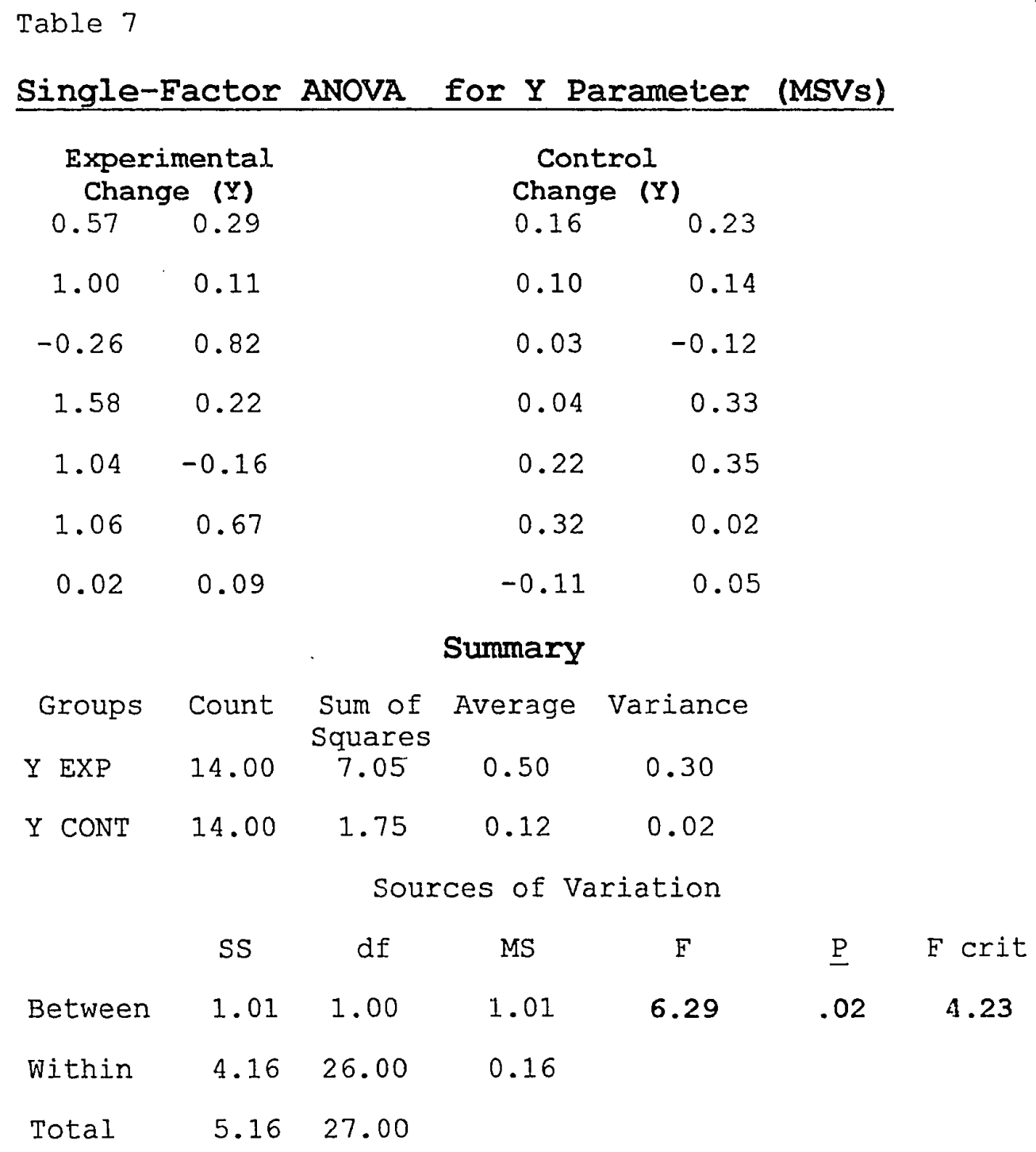


CHAPTER V

SUMMARY, DISCUSSION, CONCLUSIONS, RECOMMENDATIONS

\section{Introduction}

The majority of all previous ankle disk proprioceptive research has investigated training effects on the postural sway of subjects with a history of injury. The purpose of this study was to investigate the effects of a 10 week

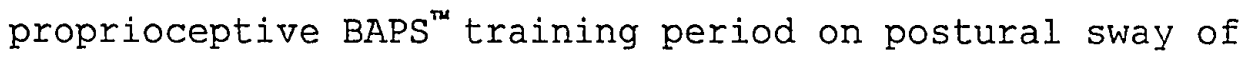
healthy subjects. The Null hypothesis was that following a 10 week BAPS $^{\text {Tu }}$ training period, subjects in the experimental group, compared to the control group, would show no significant difference in proprioception as measured through a postural sway evaluation.

\section{SUMMARY}

In summary, 28 healthy male and female subjects participated in this study. Subjects in the experimental group ( $\mathrm{N}=14)$ trained for 10 weeks at a frequency of 3 times per week for approximately $10 \mathrm{~min}$ each session. The subjects in the control group $(\mathrm{N}=14)$ did not train. The training tool was the Biomechanical Ankle Platform System 
(BAPS ${ }^{\mathrm{IM}}$ ) and the testing device was the Kistler force

platform. The force platform measured sway in the mediallateral (X) and the anterior-posterior (Y) directions. Statistically, an ANOVA (alpha $=.05$ ) was conducted on the experimental and control group's gain scores for postural sway of both parameters. Significant differences were found in both. the $\mathrm{X}$ and $\mathrm{Y}$ parameters. In conclusion, 10 weeks of BAPS $^{\text {IM }}$ training significantly decreased postural sway in the $X$ and $Y$ directions.

\section{Discussion}

The ANOVA for the medial-lateral (X) parameter, $F(1,26)=5.09, \underline{p}<.05$, and the ANOVA for the anteriorposterior ( $\mathrm{Y}$ ) parameter, $\mathrm{F}(1,26)=6.29, \mathrm{p}<.05$ indicate $\mathrm{a}$ significant difference between groups in each parameter. Normative values of force variability for postural sway evaluations using the force platform were reported by Goldie et al. (1989). The values for the medial-lateral (X) sway of subjects being tested on the preferred leg with eyes open are $2.8 \pm .6$ and the combined pre and post averages this study were $X=2.81 \pm 1.0$. For the $Y$ parameter Goldie reported normative values of $2.0 \pm .6$ compared to $2.30 \pm .8$ for this investigation. The results found here were 
remarkably similar to the results reported by Goldie. This may indicate high instrument reliability.

Proprioceptive deficits have been shown to exist following ankle injuries (Garn \& Newton, 1988; Glencross \& Newton, 1981; Tropp, Odenrick, \& Gillquist, 1985). Several authors have also demonstrated that proprioceptive ankle disk training, similar to BAPS ${ }^{\mathrm{TM}}$ training, decreases injury induced postural sway changes (Freeman et al., 1965; Gauffin et al., 1988; Tropp et al., 1984a). In this study proprioceptive training effects were investigated in a healthy population, and in agreement with previous research, a significant decrease of postural sway resulted. Three of the subjects in the experimental group and eight of the subjects in the control group showed slight increases in postural sway from pre to post testing as indicated by a negative value for the change in MSV. This phenomenon is difficult to explain, but may be due to individual subject activity on the days of testing or even possibly related to the time of day in which the subjects were tested.

\section{Conclusions}

In conclusion, a 10 week training period had a significant effect on proprioception as measured by postural 
sway. Postural sway during a modified Romberg test is a direct measure of proprioception (DeCarlo et al., 1986; Sahlstrand et al., 1978; Tropp et al., 1984).

Prcprioceptive type training of subjects heightens their postural control and may benefit human movement. When considering subjects with a history of ankle injury, both wearing an orthosis and proprioceptive training decrease the incidence of ankle injury (Tropp, Askling, \& Gillquist, 1985). These two findings support the use of proprioceptive ankle disk training for participants of athletic type activities.

\section{Recommendations}

The experimental group showed significant decreases in postural sway in both the $X$ and $Y$ directions over the control group. Therefore, in the area of human movement, proprioceptive training may be a beneficial adjunct to a physical fitness training program. However, many unanswered questions remain concerning the effects of heightened proprioception. For example, is proprioceptive training beneficial in reducing the incidence of injury?

Much more research needs to be conducted in the area of proprioceptive training for healthy subjects. Several variables were not considered in this study, and several 
areas of this study can be expanded upon. Some of the variables subject to future research are: gender, age, height, weight, and the effects on the untrained leg. Gender and age need to be investigated so that recommendations can be made population specific. Both height and weight are important because they directly affect the position of the subject's center of gravity which may be related to the ability to control postural sway. The effects on the untrained leg must be considered because if there is an induced postural sway discrepancy between the lower limbs the athlete may be at greater risk of injury. On the other hand, if there are similar effects on the untrained leg due to training carry over, the subject need only train one leg to achieve bilateral results.

In the area of specific methodological changes and considerations there are two specific recommendations. First, equal number of males and females should be assigned to each group. The subjects should be separated into gender categories and then randomly assigned to a study group. This would assure an equal number of males and females in each group and still allow for random selection. Secondly, standardization of the time of day for pre and post testing should be considered. As stated above, the effects of testing during different periods of the day may have 
affected the results of this study. In an attempt to alleviate this possible complication testing times should be standardized. 


\section{REFERENCES}

Arnheim, D.D. (1989). Modern principles of athletic training (7th ed.). St. Louis: Mirror/Mosby.

Balduini, F.C., \& Tetzlaff, J. (1982). Historical. perspectives on injuries of the ligaments of the ankle. In J.S. Torg (Ed.), Ankle and Foot Problems in the Athlete. Clinics in Sports Medicine 1 (pp. 3-12). Philadelphia: W.B. Saunders Company.

Davies, C.L. (1989). Taber's Cylopedic Medical Dictionary (16th ed.). Philadelphia: F.D Davies.

De Carlo, M. S., \& Talbot, R. W. (1986). Evaluation of ankle joint proprioception following injection of the anterior talofibular ligament. The Journal of Orthopedic and Sports Physical Therapy, $8(2), 70-76$.

Freeman, M.A.R., Dean, M.R.E., \& Hanham I.W.F., (1967). The etiology and prevention of functional instabilities of the foot. Journal of Bone and Joint Surgery, $47 \mathrm{~b}(4)$, $678-685$.

Freeman, M.A.R., \& Wyke,B. (1967). Articular reflexes at the ankle joint: An electromyographic study of normal and abnormal influence of ankle joint mechanoreceptors upon reflex activity in leg muscles. British Journal of Surgery, 54(12), 990-1000.

Frieden, T., Zantterstrom, R., Lindstrand, A., \& Moritz, U. (1989). A stabilometric technique for evaluation of lower limb instabilities. The American Journal of Sports Medicine, 17(1), 118-122.

Garn, S.N., \& Newton, R.A. (1988). Kinesthetic awareness in subjects with multiple ankle sprains. Physical Therapy, 68(11), 1667-1671.

Garrick, J.G. (1977). The frequency of injury, mechanism of injury, and epidemiology of ankle sprains. The American Journal of Sports Medicine, $\underline{5}, 241-\overline{242}$. 
Gauffin, H., Tropp, H., \& Odenrick, P. (1988). Effect of ankle disk training on postural control in patients with functional instabilities of the ankle joint. International Jcurnal of Sports Medicine, 9, 141-144.

Glencross, D., \& Thorton, E. (1981). Position sense following joint injury. Journal of Sports Medicine, $21,23-27$.

Goldie, P. A., Bach, T. M., \& Evans, O. M. (1989). Force platform measures of evaluating postural control: Reliability and Validity. Archives of Physical Medicine and Rehabilitation, 70, 510-517.

Gray, G. (1986). Rehabilitation of running injuries: biomechanical and proprioceptive considerations. Top Acute Care Trauma Rehabilitation, 1, 67-77.

Hoppenfeld,S. (1976). Physical examination of the spine and extremities. Fast Norwalk, CT: Appelton-Century-Crofts.

Lentell, G. L., Kratzman,L.L., \& Walters, M.R. (1990). The relationship between muscle function and ankle stability. Journal of orthopedic and Sports Physical Therapy, 11(12), 605-611.

Newton, R.A. (1982). Joint receptor contributions to reflexive and kinesthetic responses. Physical therapy, $\underline{62}(1), 22-29$.

MCGee, D.J. (1987) . Orthopedic physical assessment. Philadelphia: W.B. Saunders.

Roy, S., \& Irvin, R.(1983). Sportsmedicine: Prevention, evaluation, management, and rehabilitation. Englewood Cliffs, NJ: Prentice Hall.

Sahlstrand, T., Ortebgren, R., \& Nachemson, A. (1978). Postural equilibri'm in adolescent idiopathic scoliosis. Acta Orthopedics of Scandinavia, 49, 354365 . 
Soderberg, G. I., Cook, T. M., Rider, S.C., \& Stephenitch, B.L. (1991). Electromyographic activity of selected leg musculature in subjects with normal and chronically sprained ankles performing on a B.A.P.S. board. Physical Therapy, 71(7), 514-552.

Tropp H., Ekstrand, J., \& Gillquist, J. (1984a). Factors affecting stabilometery recordings of single limb stance. The American Journal of Sports Medicine, $12(3)$, 185-188.

Tropp H., Ekstrand, J., \& Gillquist, J. (1984b). stabilometery in functional instability of the ankle and its value in predicting injury. Medicine and Science in Sports and Exercise, 16(1), 64-66.

Tropp, H., Askling, C., \& Gillquist, J. (1985). Prevention of ankle sprains. The American Journal of Sports Medicine, $13(4), 12 \overline{59-262}$.

Tropp, H., Odenrick, P., \& Gillquist, J. (1985). Stabilometery readings in functional and mechanical instabilities of the ankle joint. International Journal of Sports Medicine, 6 , 180-182. 
APPENDIX A Permission Letter 


\section{Homestead High School \\ 21370 Homestead Road * Cupertino * CA • 95014-0292 \\ Tel: (408) 522-2500 - FAX: (408) 738-8631 \\ David Payne, Principal}

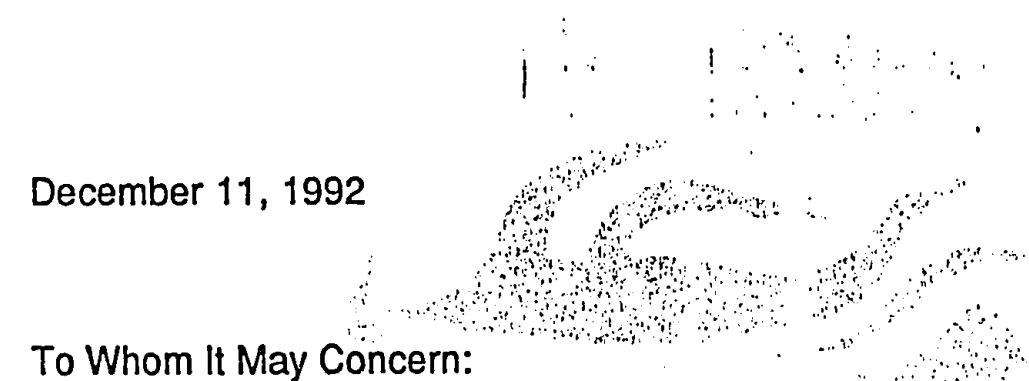

To Whom It May Concern:

Mark Hoffman has my permission to conduct his study at Homestead High School.
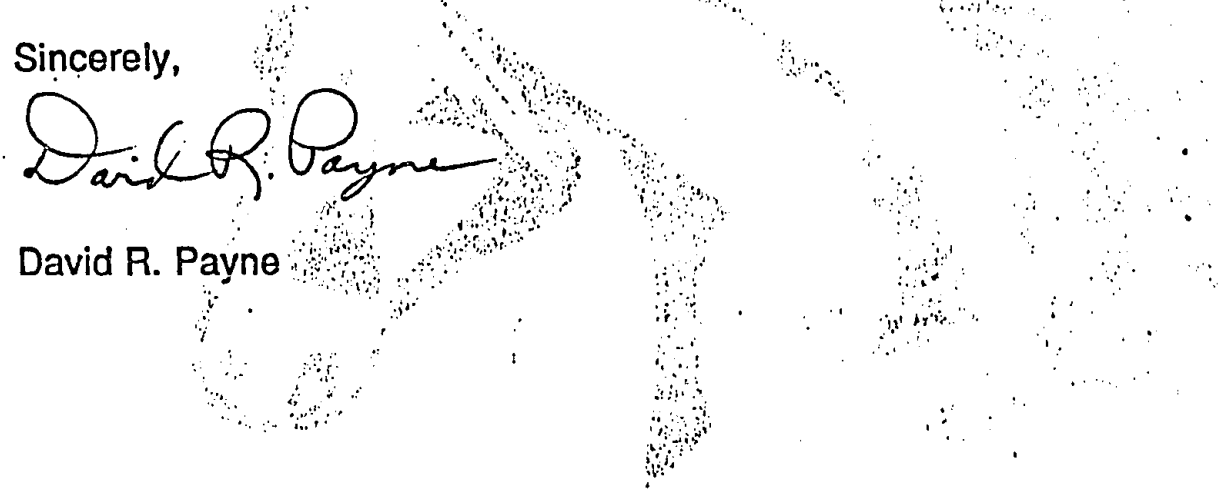
APPENDIX B

Agreement to Participate in Research 
College of Applled Sciences and Arts - Department of Human Pertormance

One Washington Square • San José, Calilornia 95192-0054 • 408/924-3010 • FAX 408/924-3053

Agreement to participate in Research

San Jose state Oniversity

Department of Human Performance

\section{Responsible Investigator (s): MARK HOFFMAN}

Title of Protocol: THE EFFECTS OF PROPRTOCEPTIVE TRATNING ON POSTURAL SFAY USTYG THE BIOMECHANICAL ANKCE PLFTTORM SYSTEM ON HEALTHY SUBJECTS.

1. I have been asked (or my child has been asked) to participate in a research gtudy investigating the effects of proprioceptive training on postural sway.

2. I will be asked to report to San Jose State University Department of Human Performance for pre and post testing. I will be involved in a training program that is to take place at Homestead High school. The program will involve proprioceptive training three times a week for 10 weeks and each session will last approximately 10 minutes. The training will be conducted during a regularly scheduled Physical Education class.

3. Due to the subject determined intensity level, the risks of injury are no greater than the risks of every day normal ambulation and activity.

4. The possible benefits associated with this study are an increased knowledge of proprioceptive training, and possibly decreasing postural sway.

5. Any questions I have associated with this research will be answered by Mark Hoffman at (408) 725-8454. Complaints about the research may be presented to Gregory Payne, P.E.D. (Thesis Advisor) at (408) 924-3028. Questions or complaints about the research, subjects' rights, or research-related injury may be presented to serena stanford, PhD., Associate Academic Vice President for Graduate Studies and Research, at (408) $924-2480$.

6. My consent is given voluntarily without being coerced; I may refuse to participate in this study or in ary part of this study, and I may withdraw at any time, without prejudice to ry relations with sJsu.

7. I have received a signed copy of this consent form for my records.

* The signature of a subject on this document indicates agreement to participate in the study.

* The signature of a researcher on this document indicates agreement to include the above named subject in the research and attestation that the subject has been fully informed of his or her rights.

Subject's signature
Date 


\section{Parental or Guardian Permission Form}

I have read the description of the study (provided on the Consent to Participate Form) and my signature on this document indicates approval for the child or ward, listed below, to participate in the indicated study. This document also serves as a statement that the child or ward is freely willing to participate.

Name of Child or Ward $\overline{\text { Parent or Guardian's Signature }} \overline{\text { Date }}$

Full Mailing Address 
APPENDIX C

Potential Subject Information Sheet 


\section{Potential Subject Information Sheet}

Name

Date

Sex: Male Female Home Phone Number

Age _ـ Weight

Have you ever (in your lifetime) sustained an INJURY (this does not include shin splints or muscle strains) to the lower extremity (hip to toes) where the symptoms persisted for longer than three days?

\section{Yes No}

Are you aware of any balance related problems that you possess?

Yes No 
APPENDIX D

Subject Information Sheet 


\section{Subject Information Sheet}

Name

Date

subject Number

Sex M F Home Phone Number

Age —_ weight

Subject Number

Group: Control Experimental 
APPENDIX E

\section{Tests Used to Determine Dominance}

1) Subjects kicked a regulation soccer ball that was rolled to them from a distance of 10 feet. The leg used to kick the ball was determined to be the dominant leg.

2) Subjects were asked to step up on an 8 inch bench. The leg placed on the bench first was determined to be their dominant leg.

3) The tester stood behind the subject and applied pressure to the center of the back until balance was lost. When balance was lost the subject was forced to step forward. The leg used to make the step forward was considered to be the dominant leg.

The leg used in at least two of the three above tests was considered to be the dominant leg used in physical activity. 


\section{APPENDIX F}

Kistler Force Platform and Modified Romberg Test
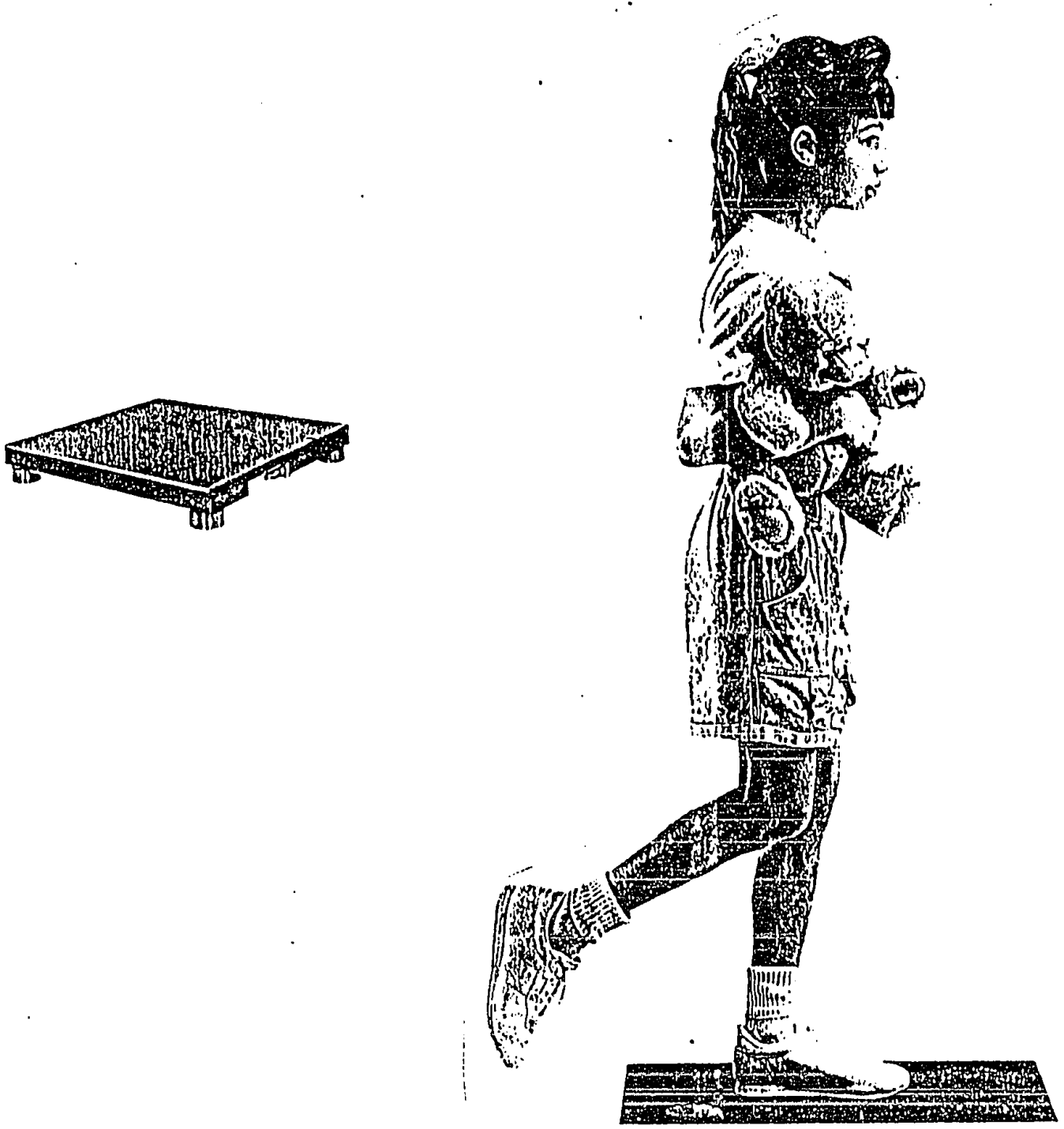
APPENDIX G

Biomechanical Ankle Platform System (BAPS ${ }^{\mathrm{TM}}$ )
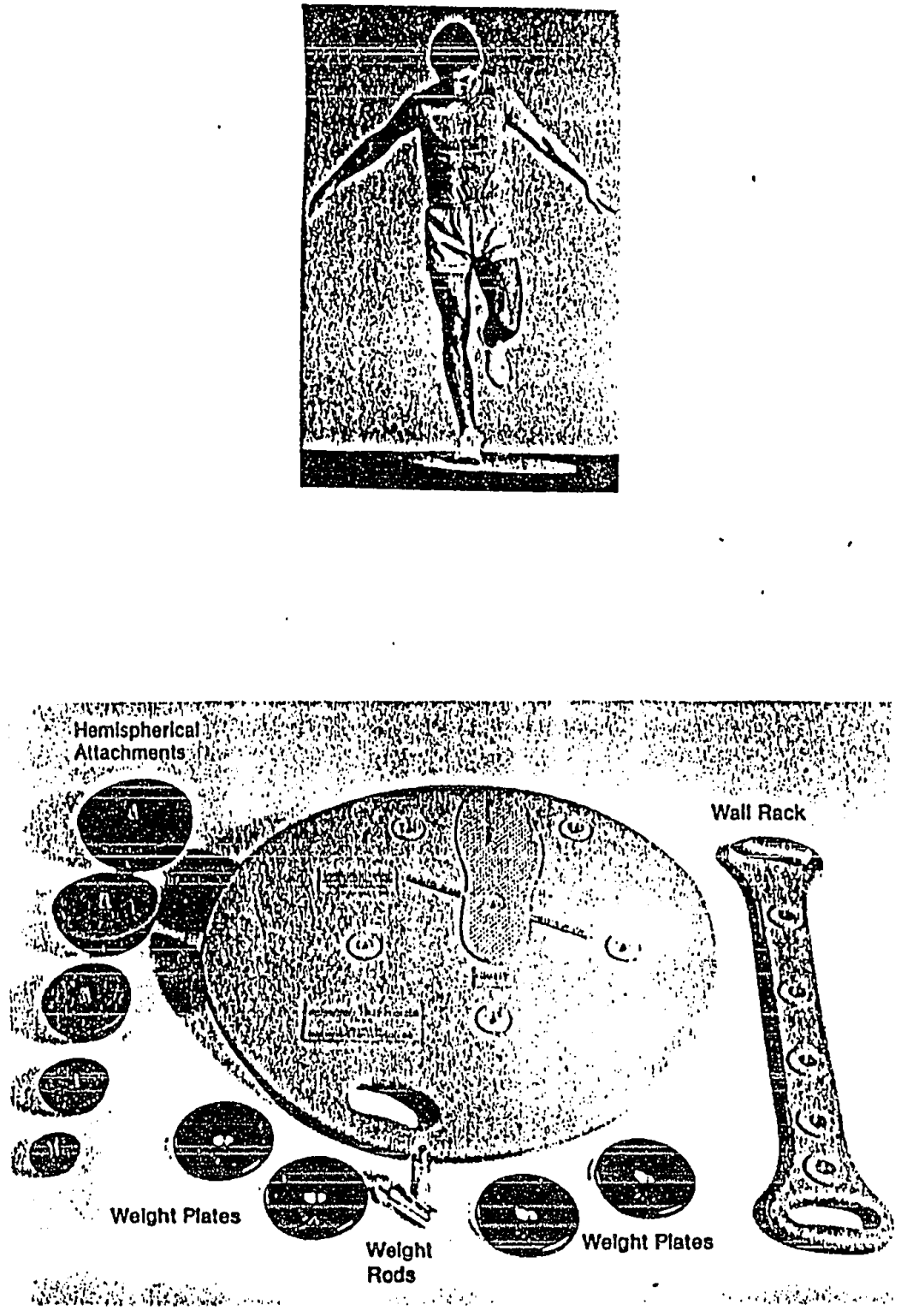